(1)

CrossMark

\title{
Challenges of evaluating lung function as part of cancer care during the COVID-19 pandemic
}

\author{
Justin L. Garner ${ }^{1,2,3}$ and Pallav L. Shah $\mathbb{1}^{1,2,3}$ \\ Affiliations: ${ }^{1}$ Royal Brompton Hospital, London, UK. ${ }^{2}$ Chelsea \& Westminster Hospital, London, UK. \\ ${ }^{3}$ National Heart and Lung Institute, Imperial College London, London, UK. \\ Correspondence: Pallav L. Shah, Royal Brompton Hospital, Sydney Street, London SW3 6NP, UK. \\ E-mail: pallav.shahdimperial.ac.uk
}

@ERSpublications

The COVID-19 pandemic and the necessity for social isolation are ushering in a new era of remote clinical evaluation. Modifications of CT imaging and processing in chest medicine yield both anatomical and functional information in a safe environment. https://bit.ly/2Np3Dyz

Cite this article as: Garner JL, Shah PL. Challenges of evaluating lung function as part of cancer care during the COVID-19 pandemic. Eur Respir J 2020; 56: 2001621 [https://doi.org/10.1183/13993003.016212020].

Severe acute respiratory syndrome coronavirus 2 (SARS-CoV-2) is a newly identified agent foisted upon humanity and responsible for the contagious affliction, coronavirus disease 2019 (COVID-19) [1] that has rapidly evolved into a pandemic testing to the limits, and sometimes beyond, the capacity to respond of healthcare systems across the world [2]. Management is purely supportive and social isolation crucial to containment [3]. Enforced reallocation of hospital resources and personnel to cope with the increasing numbers requiring hospital admission and intensive care [4] in the most trying of conditions has been at the expense of many hospital departments, among them those offering diagnostic and support services for lung cancer [5-7].

Evaluation of lung physiology is an essential preliminary to potentially curative treatments, surgical resection, chemotherapy and radiotherapy [8]. The risks to patients and staff associated with exposure to aerosols generated by forced expiratory manoeuvres in conventional testing has led to several societies issuing advice against their use [9, 10]: formal evidence-based guidance has yet to be published. Our institution is, however, adapting to less hazardous procedures and technologies, for example virtual clinical assessments.

Spirometry is the most feared aerosol generating procedure and we are looking into provision of peak expiratory flow meters to be used as an alternative in the home environment [11]. Remote monitoring of cystic fibrosis patients with portable wireless transmission spirometers such as NuvoAir has revolutionised their outpatient management, and minimising interpersonal contact, has the potential for transforming the care of cancer patients during the current "lockdown" period [12]. Use of either device can be supervised via a secure telemedicine link to ensure optimal technique and valid measurements and provide convenient, operationally and financially advantageous continuing surveillance of these patients, particularly post-operatively.

A promising alternative approach to evaluating lung function is that of quantitative computed tomography (qCT) imaging [13]; whilst this is currently a research tool, it has the potential for transforming clinical 


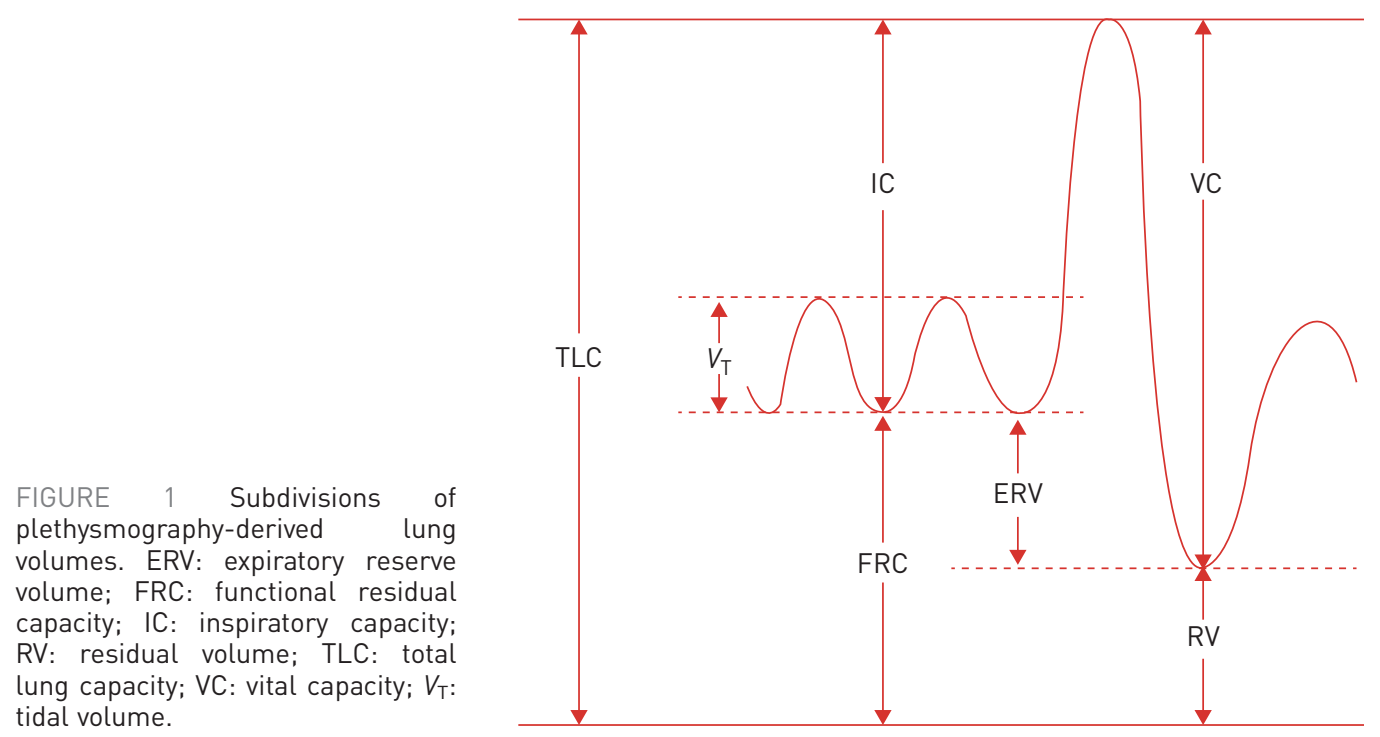

practice. Fractionation of conventional CT scans on a scale of attenuation has been used to determine the relative contributions of pathologies. SHroeder et al. [14], in 2013, examining more than 4000 CT scans made in expiration of individuals who were smokers, with and without COPD, correlated air trapping (areas of low attenuation equal to or less than -856 Hounsfield units, HU) with physiological measures of airway obstruction. Their estimations of forced expiratory volume in $1 \mathrm{~s}\left(\mathrm{FEV}_{1}\right)$ compared favourably with those of spirometry. Wu et al. [15], in 2002, categorising the pre-operative scans of 44 of their lung cancer patients, applied dual thresholds of attenuation distinguishing the contributions of tumour and atelectasis (greater than $-500 \mathrm{HU}$ ), emphysema (less than $-910 \mathrm{HU}$ ), and normal functioning parenchyma $(-500$ to $-910 \mathrm{HU})$ and making accurate predictions of post-operative $\mathrm{FEV}_{1}$. The authors, observing the small sample size, exercised caution in those patients with a qCT-predicted $\mathrm{FEV}_{1}<40 \%$ who have a higher risk of post-operative morbidity and mortality, and advised the addition of perfusion scintigraphy and exercise testing for comprehensive evaluation. Functional respiratory imaging, combining high-resolution $\mathrm{CT}$ and post-processing computational fluid dynamics, can be used to assess airway volume and resistance at a lobar level and is more sensitive to pharmacologically induced changes than routine lung function tests [16]. Total lung capacity and residual volumes, estimated on CT scans respectively made in maximum inspiration and expiration have also been shown to correlate well with plethysmography derived measurements (figure 1) [17]. In the absence of a local qCT software platform, a number of commercial companies offer such an imaging service simply requiring uploading of an anonymised CT scan to a secure cloud-based service for analysis: the report is emailed within $24 \mathrm{~h}$.

Dual-energy phase CT [18] and single photon emission tomography CT [19] imaging enable evaluation of lobar perfusion, which is necessary, for example, prior to surgery. Furthermore, CT chest images acquired without electrocardiographic gating for non-cardiac indications have nevertheless proved serviceable for detecting coronary artery calcification $[20,21]$ and quantifying epicardial and thoracic fat [22].

The COVID-19 pandemic and the necessity for social isolation is ushering in a new era of remote clinical evaluation. Modifications of CT imaging and processing in chest medicine yield both anatomical and functional information in a safe environment. They are not expected to appreciably add to the radiation exposure of current use, nor are they likely to be especially time-consuming $[23,24]$. This approach could be transferable to other fields of medicine. The advent of serological testing for SARS-CoV-2 should help to restore some functionality to the health services, but a rethinking of current infrastructure and adaptation to the demands of changing global circumstances confronting us is called for.

Author contributions: P.L. Shah conceived the topic. J.L. Garner and P.L. Shah wrote the manuscript.

Conflict of interest: J.L. Garner has nothing to disclose. P.L. Shah has nothing to disclose.

\section{References}

1 Gorbalenya AE, Baker SC, Baric RS, et al. The species severe acute respiratory syndrome-related coronavirus: classifying 2019-nCoV and naming it SARS-CoV-2. Nat Microbiol 2020; 5: 536-544. 
2 Sohrabi C, Alsafi Z, O’Neill N, et al. World Health Organization declares global emergency: a review of the 2019 novel coronavirus (COVID-19). Int J Surg 2020; 76: 71-76.

3 Pascarella G, Strumia A, Piliego C, et al. COVID-19 diagnosis and management: a comprehensive review. J Intern Med 2020; 288: 192-206.

4 Emanuel EJ, Persad G, Upshur R, et al. Fair allocation of scarce medical resources in the time of Covid-19. $N$ Engl J Med 2020; 382: 2049-2055.

5 Ueda M, Martins R, Hendrie PC, et al. Managing cancer care during the COVID-19 pandemic: agility and collaboration toward a common goal. J Natl Compr Canc Netw 2020; 18: 366-369.

6 Calabrò L, Peters S, Soria J-C, et al. Challenges in lung cancer therapy during the COVID-19 pandemic. Lancet Respir Med 2020; 8: 542-544.

$7 \quad$ Burki TK. Cancer guidelines during the COVID-19 pandemic. Lancet Oncol 2020; 21: 629-630.

8 Lim E, Baldwin D, Beckles M, et al. Guidelines on the radical management of patients with lung cancer. Thorax 2010; 65: Suppl .3, iiil-iii27.

9 Association for Respiratory Technology and Physiology. ARTP COVID19 Update - 18th March 2020. www.artp. org.uk/News/artp-covid19-update-18th-march-2020 Date last updated: 18 March 2020.

10 McCormack MC, Kaminsky DA. Pulmonary Function Laboratories: Advice Regarding COVID-19. www.thoracic. org/professionals/clinical-resources/disease-related-resources/pulmonary-function-laboratories.php

11 Nair S, Padmanabhan A, Kumari A. Peak-flow or portable spirometry as a replacement for Spirometry in the diagnosis of COPD and Asthma. Eur Respir J 2018; 52: Suppl. 62, PA906.

12 Shakkottai A, Nasr SZ. The use of home spirometry in pediatric cystic fibrosis patients: results of a feasibility study. Glob Pediatr Health 2017; 4: 2333794X17690315-2333794X.

13 Newell JD Jr, Sieren J, Hoffman EA. Development of quantitative computed tomography lung protocols. J Thorac Imaging 2013; 28: 266-271.

14 Schroeder JD, McKenzie AS, Zach JA, et al. Relationships between airflow obstruction and quantitative CT measurements of emphysema, air trapping, and airways in subjects with and without chronic obstructive pulmonary disease. AJR Am J Roentgenol 2013; 201: W460-W470.

15 Wu MT, Pan HB, Chiang AA, et al. Prediction of postoperative lung function in patients with lung cancer: comparison of quantitative CT with perfusion scintigraphy. AJR Am J Roentgenol 2002; 178: 667-672.

16 De Backer W, De Backer J, Vos W, et al. A randomized study using functional respiratory imaging to characterize bronchodilator effects of glycopyrrolate/formoterol fumarate delivered by a metered dose inhaler using co-suspension delivery technology in patients with COPD. Int J Chron Obstruct Pulmon Dis 2018; 13: 2673-2684.

17 Shen M, Tenda ED, McNulty W, et al. Quantitative evaluation of lobar pulmonary function of emphysema patients with endobronchial coils. Respiration 2019; 98: 70-81.

18 Pansini V, Remy-Jardin M, Faivre JB, et al. Assessment of lobar perfusion in smokers according to the presence and severity of emphysema: preliminary experience with dual-energy CT angiography. Eur Radiol 2009; 19: 2834-2843.

19 Wechalekar K, Garner J, Gregg S. Pre-surgical evaluation of lung function. Semin Nucl Med 2019; 49: 22-30.

20 Hughes-Austin JM, Dominguez A 3rd, Allison MA, et al. Relationship of coronary calcium on standard chest CT scans with mortality. JACC Cardiovasc Imaging 2016; 9: 152-159.

21 Hecht HS, Cronin P, Blaha MJ, et al. 2016 SCCT/STR guidelines for coronary artery calcium scoring of noncontrast noncardiac chest CT scans: a report of the Society of Cardiovascular Computed Tomography and Society of Thoracic Radiology. J Cardiovasc Comput Tomogr 2017; 11: 74-84.

22 Dey D, Nakazato R, Li D, et al. Epicardial and thoracic fat - noninvasive measurement and clinical implications. Cardiovasc Diagn Ther 2012; 2: 85-93.

23 Henzler T, Fink C, Schoenberg SO, et al. Dual-energy CT: radiation dose aspects. AJR Am J Roentgenol 2012; 199: 5_Suppl., S16-S25.

24 Tao SM, Li X, Schoepf UJ, et al. Comparison of the effect of radiation exposure from dual-energy CT versus single-energy CT on double-strand breaks at CT pulmonary angiography. Eur J Radiol 2018; 101: 92-96. 